\title{
Private International Space Law. Philosophical and Legal Factors of Approval by the World Community
}

\author{
Valentyn Halunko \\ Doctor of Law, Professor, President of the Research Institute of Public Law \\ (Kyiv, Ukraine) \\ E-mail: halunko@i.ua \\ https://orcid.org/0000-0003-1619-5028 \\ Serhii Didenko \\ Doctor of Law, Associate Professor, Director of Kherson Institute of \\ "Interregional Academy of Personnel Management" \\ (Kherson, Ukraine) \\ E-mail: sergii_didenko@ukr.net \\ https://orcid.org/0000-0003-3349-4046
}

This paper reveals the philosophical and legal factors of the private international space law. It is concluded that the world community should develop and approve private international space legislation and law, even before the mass use of space by individuals and colonization of space bodies. It is proved that the research, use and legal protection of outer space, space bodies and space colonization is an objective irrevocable and progressive phenomenon of mankind. It should be implemented on the basis of both public and private international space law. It is revealed that the first is well developed, and the second is at the stage of philosophical and legal approval. The authors emphasize that otherwise; the situation will be able to go beyond the humanistic and legal dimensions. This process might become uncontrollable, lead to space piracy, space wars, violation of people's right to life and health, violation of property rights, in particular, intellectual property rights.

Keywords: space colonization; space law; legislative processes; outer space; humanity; private international space law

Received: August 20, 2018; accepted: October 11, 2018

Philosophy and Cosmology, Volume 22, 2019: 16-23.

https://doi.org/10.29202/phil-cosm/22/2

(C) Halunko, Valentyn, 2019

(C) Didenko, Serhii, 2019 


\section{Introduction}

The dynamic development of science, new technologies and new materials, and the creation of elements of artificial intelligence enable humanity in the medium term not only to explore outer space but also to be safe, work, relax and create outside the planet Earth. Mankind is successfully studying the interplanetary space of the Solar system. For the first time, the Voyager 1 and Voyager 2 spacecraft have left the Solar system. Thanks to the images of the Hubble Space Telescope, the world learned about the existence of exoplanet, about the suitability of life on planets outside the solar planet. For example, in Hubble Space Telescope search for the transit of the Earth-mass exoplanet $\alpha$ Centauri $B$, the authors consider a search for the transit of the Earth-mass exoplanet $\alpha$ Centauri B b with the Hubble Space Telescope (HST) [Demory et al., 2015]. There is a brief history of exoplanet science. Discover different types of an exoplanet, a new class of planets that allow you to explore their typical compositions and formation histories. For example, in the article A Large Hubble Space Telescope Survey of Low-Mass Exoplanets, the authors considered short-period planets with masses and radii between Earth and Neptune [Benneke, 2016]. The global space economy reached $\$ 330$ billion in 2015 , with a growth rate of 9 per cent vis-à-vis the previous year [Routledge Handbook, 2016]. Space exploration has become not only commonplace but also the essence of man. As Oleg Bazaluk notes, man is not a planetary force, but a rational matter (Intelligent-Matter), the essence of the Universe [Bazaluk, 2016].

However, in the field of space exploration natural and technical Sciences are much ahead of the Humanities. For a long time, it was natural. After all, only States had the technical and financial ability to create spacecraft and bring them into the Earth orbit. Today, space exploration and use of the Space is carried out by technically developed countries with a large economic resource like the USA, China, Great Britain, France and India. Nevertheless, some countries (Ukraine, the Russian Federation) are keeping space technologies, which were inherited from the Soviet past. Other countries such as Japan, Brazil, Iran, Israel, South Korea and North Korea have successfully begun to compete with mentioned countries in the field of space exploration and use. It has not only scientific but also business interest. An analysis of the innovation infrastructure of the countries, which are involved in space research, has shown that their level has a positive impact on business [Zharikov et al., 2017].

It is well-known fact that the State always loses in competition with the Business. In the competitive business struggle between state property and private property, the business created on the basis of private property always wins. This will objectively lead to the fact that in the future, the use of outer space, including the colonization of space bodies (planets, satellites and others) will be carried out at the expense of private financing, in order to make a profit. For instance, the private company SpaceX, founded by Elon Musk, successfully launches new cheaper and more efficient rockets one after another [Musk, 2017]. To date, the main customers for the launch of the artificial Earth satellites into orbit are still States that are increasingly using private missiles for this purpose. Very soon, the situation will change. The private rocket will put into orbit a private satellite. Private companies will send space expeditions to the Moon and other planets of the Solar system. For example, Musk emphasizes the question: "So how do we figure out how to take you to Mars and create a selfsustaining city - a city that is not moderately an outpost but which can become a planet in its own right, allowing us to become a truly multi-planetary species?" [Musk, 2017]. According to our scientific research, humanity has entered the era of private exploration, exploration and colonization of the Space. Therefore, humanitarian research in the field of private space exploration and colonization should develop exponentially. The final result of development 
should be the adoption of "private space rules" and "private space law." This process is objective it is impossible to stop it.

The growing number of humanity needs more and more natural resources of the Space to survive. In the Chapter the Importance of Natural Resources from Space and Key Challenges, the authors explain the rate at which rare natural resources are being consumed by a global population that is expanding in twenty-first century Howard 12 billion people. There demand for space raw materials has appeared, for instance, rare valuable natural resources such as platinum abundantly available in space, but so are water and other vital resources. The authors emphasize that the hydrogen and oxygen in "space water" can be used as rocket fuel [Jakhu et al., 2017]. Private capital is taking successful steps in using the Space for profit. For example, in the Chapter Private Sector Space Mining Initiatives and Policies in the United States, the authors state that "The private space companies were able to build their new space mining companies on the base of U. S. government space programs that have been active for a half century" [Jakhu et al., 2017: 59]. The authors provide an insight into the many U. S. space missions conducted in past decades to explore the Solar System and its composition and character. This key exploratory information plus new contracts by NASA to the start-up private space mining activities represented vital support to the various space mining ventures [Jakhu et al., 2017]. In the absence of private space law, this cannot be done without human rights violations.

Consequently, the relevance of this paper is justified by a number of factors, the leading of which is to counter violations of the rights, freedoms and legitimate interests of people in the Cosmic space, in particular on colonized objects; not allowing space wars and space piracy, solving the global problem of human survival outside the planet Earth.

\section{The need for the law for space exploration, mining of natural resources on space objects and space colonization}

The attraction of private capital into Space is an objective and irreversible phenomenon. This should solve both the global problems of mankind and the subjective interests of private companies investing in space exploration. In the second case, it is very important that "space private companies" do not violate the public interest of mankind and the legitimate interests of other businessmen as well as the environmental norms.

Therefore, in order for humanity to survive, we must move some people to a new space house outside of planet Earth. However, the conquest of the Universe by people is a long process. People have to put a lot of efforts to colonize Moon and Mars. As Elon Musk "to make Mars trips possible on a large, enough scale to create a self-sustaining city study shows, full reusability is essential. Full reusability is really the super-hard one. It is very difficult to achieve reusability even for an orbital system, and that challenge becomes substantially greater for a system that has to go to another planet" [Musk, 2017]. As a comparison, Musk cites the cost of a ticket from Los Angeles to Vegas for $\$ 43$, on an aircraft that costs $\$ 90$ million. This ticket price is due to the regularity of flights and long operating time of the aircraft. If this flight were a one-way trip, the cost of the ticket would be $\$ 500,000$ [Musk, 2017]. Given that the EarthMars rendezvous only occurs every 26 months, the spacecraft (the spaceship) can be used every two years. However, how long will it last? For Musk, Mars exploration is just a business. Musk considers a revolutionary breakthrough in the history of human culture only from the point of view of economic expediency and profit. This is a completely new approach that has become a reality. From the romantic perception of space flights, humanity has moved to economic calculations and the assessment of business interests. 
If in the $20^{\text {th }}$ century, the exploration and use of space were exclusively of a state nature, the situation has changed dramatically in the crisis. Private companies have become the main actors in the use of outer space, the extraction of minerals from comic objects and the colonization of planets and satellites. Therefore, it is on the planet Earth, even before the beginning of the broad implementation of private company space exploration should be created laws of the development of cosmic space by individuals. Therefore new space legal norms shall be created on the planet Earth before the massive private space colonization. Space exploration is a very important part of science which includes studying the natural extinction of Earth [Yatskiv, 2007]. In our opinion, the laws of the development of cosmic space by individuals are approved as international regulations of the United Nations.

In recent decades, we have seen rapid changes and significant expansion in space law, especially at the national level of individual States. As noted by the authors of the Routledge Handbook of Space Law in the last decade, space States are adopting more and more laws and regulations. In turn, other countries are adopting national Space Laws and regulations related to regulating activities in outer space. Under the auspices of reputable international organizations, new regulatory bodies are being created, which strengthen the regulatory diversity from public law to private law. At the international level, space law (both hard law and soft law) is expanding in certain areas, especially in satellite broadcasting and telecommunications [Routledge Handbook, 2016].

The private space industry is developing rapidly. This is confirmed by the annual Space Products and Services Overview (https://www.thespacereport.org/). Humanity needs laws for space exploration by individuals, for mining on natural space objects and space colonization. The need for laws for space exploration by individuals is justified by the following:

1. The attraction of private capital in space is an objective and irreversible phenomenon. This is a factor in solving the global problem of human survival, as a reasonable species, and the thirst for profit business.

2. Private companies will gradually take up a much larger share of the market for the use of outer space.

3. Private companies have become the main actors in the use of outer space, the extraction of minerals from cosmic objects and the colonization of planets and satellites.

4. On the planet Earth, even before the beginning of the broad implementation of private companies space exploration should be created laws of the development of cosmic space by individuals.

5. The laws governing the exploration of outer space by private individuals should be adopted as international instruments of the United Nations and not as national legislation of individual States.

\section{Legislative processes in the domestic and international context}

In the context of legal regulation of research and use of outer space by States (state-owned companies) is quite well developed and structured. World society has developed, approved, and parliaments of the vast number of sovereign States have ratified them. Five basic international space treaties and several additional (clarifying) treaties are now universally recognized [United Nations, 2002]:

1. Declaration of Legal Principles Governing the Activities of States in the Exploration and Use of Outer Space, adopted on 13 December 1963 (resolution 1962 (XVIII));

2. Principles Governing the Use by States of Artificial Earth Satellites for International Direct Television Broadcasting, adopted on 10 December 1982 (resolution 37/92); 
3. Principles Relating to Remote Sensing of the Earth from Outer Space, adopted on 3 December 1986 (resolution 41/65);

4. Principles Relevant to the Use of Nuclear Power Sources in Outer Space, adopted on 14 December 1992 (resolution 47/68);

5. Declaration on International Cooperation in the Exploration and Use of Outer Space for the Benefit and in the Interest of All States, Taking into Particular Account the Needs of Developing Countries, adopted on 13 December 1996 (resolution 51/122).

They are all part of international space law. Space law is part of the system of public international law. Much of the "General international law" also applies to space research. In addition, space law consists of national laws that are interlinked with the international system. In our view, such a right has the name "public international space law" to distinguish it from private international space law.

Public international space law should be based on procedures and processes that make it possible for States to develop and approve and for States to ratify public international space law. Such rules of law become binding on any international legal entity engaged in the development of the cosmic space. In addition, sovereign States adopt their own national laws on the basis of international public regulations. These norms, provided that they are not contrary to international law, become a system of public international space law. However, only within the jurisdiction of a certain sovereign state. From this perspective, having a deep insight into the doctrine of sources in public international law is essential with a view to clarify what is binding in space law and what is mere interpretation or assertion [Routledge Handbook, 2016]

The national legal systems of sources of law define the basic legislative principles and legal instruments for the exploration and use of outer space, which applies to national companies and to individuals who are under the jurisdiction of a sovereign state. However, such rules of law do not apply to subjects of law located in the jurisdiction of other States. In other words, domestic space law applies within the jurisdiction of a particular sovereign state. For example, in the United States, the Federal aviation administration (FAA) has been given certain legal authority by the Federal government to issue launch licenses to U.S. and foreign companies wishing to use U.S. launch services to spacecraft companies.

Even if the public national space legislation of a powerful space sovereign state may have some influence on foreign companies or on space law relations between sovereign States, they may not issue public space laws that would be acting outside the jurisdiction of a particular state or at the international level. Each state is sovereign, that is, no state can impose its own legislation on another. This is both a limit on national sovereignty and also protection of it, and apart from being strongly asserted by States, it is also guaranteed in Article 2(7) of the Charter of the United Nations (UN). Nothing contained in the present Charter shall authorize the United Nations to interview in matters, which are essentially within the domestic jurisdiction of any state or shall require the Members to submit such matters to settlement under the present Charter [Routledge Handbook, 2016].

In recent decades, there has been a growing number of non-state actors, such as international organizations, corporate entities and individuals, who play an increasingly important role at the international level in many areas of law. For example, human rights, environmental law, the law on armed conflict, international investment and trade. These areas of law are also relevant to space activities. Today, international law is recognized as the order governing international and transnational relations, including non-state actors. Meanwhile, the official understanding of the processes of law-making in international law still defines the initiative of States as a single entity 
of international legislative initiative. However, more and more private international community insists that international civil society actors should be given the right to international legislative initiative. One example in space law is the highly influential role played by commercial and private entities as "sector members" of the International Telecommunications Union (ITU), where regulations are made regarding the registration and protection of orbital slots and radio frequencies [Routledge Handbook, 2016].

Thus, the analysis of legislative processes in the domestic and international context regarding the norms of space law makes it possible to assert that:

1. The norms of public international space law are quite fully and thoroughly developed and recognized by the UN member States.

2. This makes it possible to avoid legal incidents to sovereign States throughout the exploration and use of outer space.

3. Nowadays, more and more private companies have the opportunity to carry out the development and use of outer space and space bodies. The dominance of the private sector in space exploration is becoming crucial.

4. This requires a legal settlement, through the development of private international space legislation and the formation on this basis of the branch of international law international private space law.

\section{Consequences of the lack of legal rules of conduct for individuals in space}

As the authors have shown above, public international law well regulates the exploration and use of outer space by States. However, more and more private companies and individuals are making real or virtual use of comic space and space bodies. So far, private companies are working closely with the relevant national structures. For example, SpaceX works closely with NASA. It works for profit, but according to public international and national space laws of the United States. Accordingly, while significant problems in this area do not arise.

However, after the withdrawal of the orbit of the Earth by the SpaceX company of about 12 000 satellites that will give away "free" Internet traffic of all comers, problems without doubt arises. First of all, it will be connected with the protection of intellectual property rights and counter-terrorism. The such States, such as China and Russia, will be categorically against all available Internet because they profess the theory and practice of the state-controlled Internet. In other words, the activities of a private company that will operate under soft (softlaw) space law will conflict with the national laws of sovereign States. Consequently, in the context of private companies and individuals, when using space, they enjoy soft law and act in accordance with a constitutional principle of English law: "Everything which is not forbidden is allowed".

Even more, there is a violation of the principle of justice and sometimes common sense about the virtual use of cosmic bodies. For example, Dennis M. Hope, the formal owner of the Moon since 1980. In 2015, two private companies, Moonestates and Moonlife Ltd, merged and merged is bring together the community of over 6 million space enthusiasts that have purchased land on the Moon (https://www.moonestates.com/about-us/). MoonEstates.com, and Moonlife Ltd view the "legalities" of selling extraterrestrial property and are quite legally valid in the U.S.A. legislative field (https://www.moonestates.com/about-us/space-law/).

From our point of view, it is unacceptable that individuals and organizations that do not enjoy any legitimacy from society should (albeit virtually) use or dispose of space objects as their property. This is a direct road to the future confrontation for the natural resources 
of space. The worst consequence of which can be real space wars. Philosophy of War and Peace, as well as its influence on the formation of the foundations of national and planetary security strategies, are considered in the study Philosophy of War and Peace: in Search of New European Security Strategy [Bazaluk \& Svyrydenko, 2017]. Private international space law, adopted by the international community through the legalization in the UN, has the right to regulate the activities of individuals about comic objects.

Consequently, the lack of legal rules of conduct for individuals in space leads to two main types of incidents:

1. Not the settlement of the right of private ownership of space bodies, will not lead to the fair capture of space bodies by persons who do not have the right to do so, and the redistribution of such objects will objectively lead to space wars.

2. Not controlled by the right of private companies to use the near-earth space will lead to a threat to the life and health of the inhabitants of the Earth, negative environmental consequences and legal conflicts, both interstate and private.

\section{Conclusions}

Researching, using, legal protection of cosmic space and cosmic objects and space colonization is an objective irrevocable and progressive phenomenon of modern humanity. It should be implemented on the basis of both public and private international cosmic law. The first is quite well developed, and the second is at the stage of philosophical and legal approval. Cosmic private international law should be crushed and approved by the international community, even before the mass exit of individuals and private companies in the space. The ownership of space objects by individuals should be acquired transparently and fairly, depending on the efforts (means) expended and in strict accordance with the rules of private international space law. Otherwise, the situation will be able to go beyond the humanistic and legal dimension. This process can become uncontrollable through space piracy and space wars, violation of people's right to life and health, violation of property rights, including intellectual property rights.

\section{[D] References}

Bazaluk, Oleg. The Theory of Evolution: From a Space Vacuum to Neural Ensembles and Moving Forward. Cambridge Scholars Publishing, 2016.

Bazaluk, Oleg and Denys Svyrydenko. Philosophy of War and Peace: In Search of New European Security Strategy. Anthropological Measurements of Philosophical Research, 12, 2017: 89-99. https://doi.org/10.15802/ampr.v0i12.119150

Benneke, Björn, Ian Crossfield, Heather Knutson, Joshua Lothringer, Peter R. McCullough, Diana Dragomir, Caroline Morley and Eliza Kempton. A Large Hubble Space Telescope Survey of Low-Mass Exoplanets. American Astronomical Society, DPS meeting \#48, 2016.

Demory, Brice-Olivier, David Ehrenreich, Didier Queloz, Sara Seager, Ronald Gilliland, William J. Chaplin, Charles Proffitt, Michael Gillon, Maximilian N. Günther, Björn Benneke, Xavier Dumusque, Christophe Lovis, Francesco Pepe, Damien Ségransan, Amaury Triaud and Stéphane Udry. Hubble Space Telescope search for the transit of the Earth-mass exoplanet $\alpha$ Centauri B b. Monthly Notices of the Royal Astronomical Society, Volume 450, Issue 2, 21 June 2015: 2043-2051. https://doi.org/10.1093/ mnras/stv673 
Jakhu, Ram S., Joseph N. Pelton, and Yaw Otu Mankata Nyampong. The Importance of Natural Resources from Space and Key Challenges. Space Mining and Its Regulation. Springer Praxis Books, 2017: 11-21. https://doi.org/10.1007/978-3-319-39246-2_2

Jakhu, Ram S., Joseph N. Pelton, and Yaw Otu Mankata Nyampong. Private Sector Space Mining Initiatives and Policies in the United States. Space Mining and Its Regulation. Springer Praxis Books, 2017: 59-71. https://doi.org/10.1007/978-3-319-39246-2_6

Musk, Elon. Making Humans a Multi-Planetary Species. New Space. Vol. 5, No. 2, 2017. https://doi.org/10.1089/space.2017.29009.emu

Routledge Handbook of Space Law. Edited by Ram S. Jakhu, Paul Stephen Dempsey. Routledge, 2016.

United Nations Treaties and Principles on Outer Space. United Nations, New York, 2002. http://www.unoosa.org/pdf/publications/STSPACE11E.pdf

Yatskiv, Yaroslav. First steps of the international cooperation in space exploration. (19571987). Space Science and Technology. № 5 (48), 2007: 21-27. http://knit.mao.kiev. ua/uk/archive/2007/5/03

Zharikov, I., Vorotnikov, V., Koukoushkin, T. Technology Transfer as a Tool for the Intellectual Property Commercialization by Developers of High-Tech Innovations. Space Science and Technology. 4 (107), 2017: 52-60. https://doi.org/10.15407/knit2017.04.052 